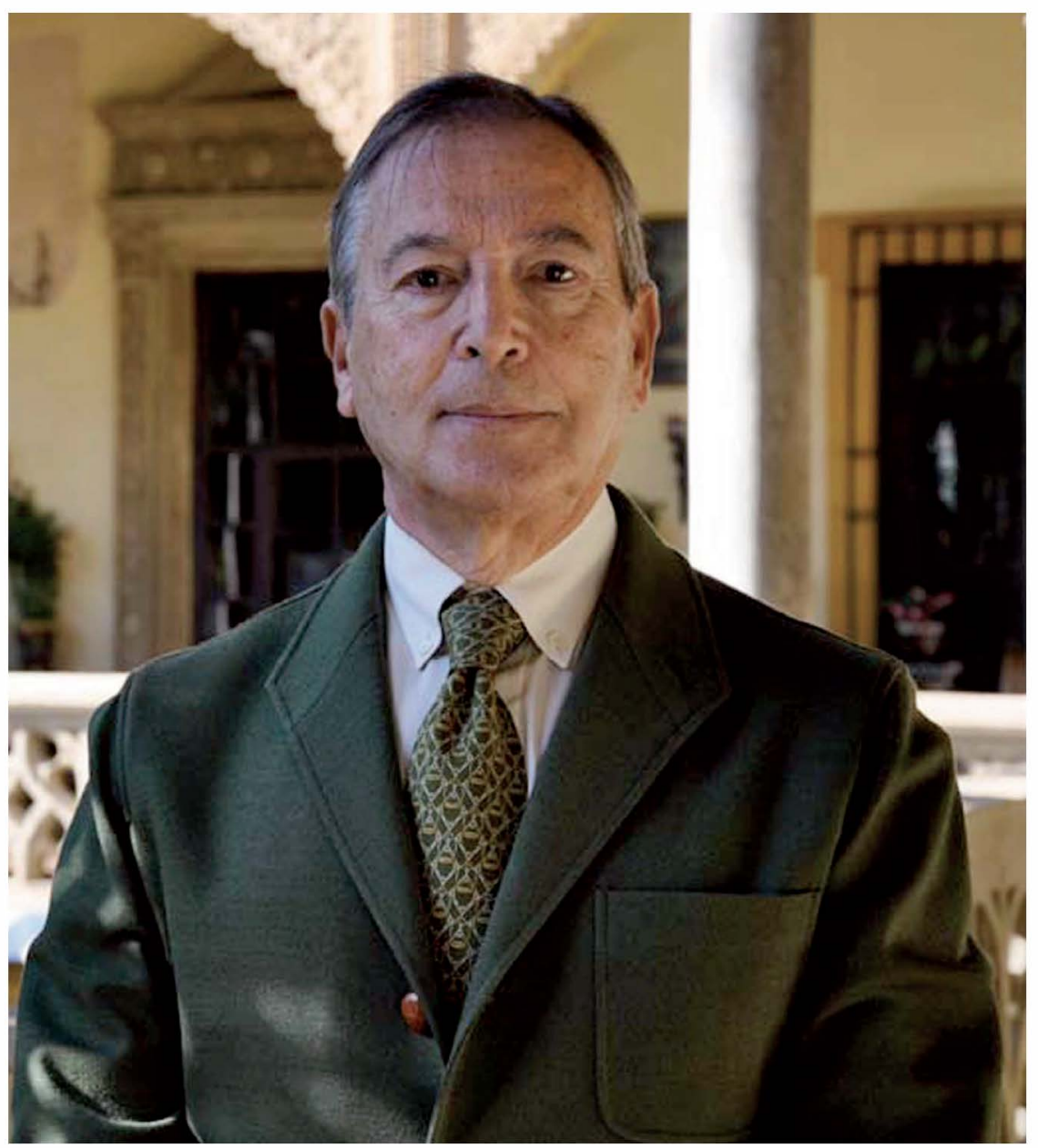




\title{
HOMENAJE AL CATEDRÁTICO EMÉRITO PROFESOR TEODORO FALCÓN MÁRQUEZ
}

\author{
FERnANDo CRUz IsIDORO
}

Cuando salga este número 27 de la revista Laboratorio de Arte, en el otoño de 2015, habrá culminado la labor docente como catedrático emérito del profesor Teodoro Falcón Márquez, iniciada hace justo medio siglo, en 1965, año en el que nacía quien escribe esta laudatio, una larga y brillante carrera en la docencia universitaria que ha desarrollado en paralelo con una prolija y apabullante labor de investigación, resuelta en más de cuarenta libros, cincuenta capítulos de libros y un largo centenar de artículos, con un perfil muy definido, como estudioso de la historia de la arquitectura andaluza, que le ha llevado a ser considerado verdadero especialista en la materia a nivel nacional, y a declararlo maestro no pocos profesores universitarios, entre ellos varios componentes de nuestro Departamento, que nos sentimos orgullosos de sus enseñanzas, ejemplo y amistad.

Por ello no resulta difícil realizar esta breve semblanza biográfica, profesional y bibliográfica, pues todos lo conocemos en mayor o menor medida.

Su nacimiento tuvo lugar en la Sevilla de 1941 y, atendiendo a su futuro profesional, en un ambiente que marcaría buena parte de su trayectoria, el colegio "San Vicente Mártir", en la calle Mármoles, donde vivían sus padres, y del que su progenitor era director-fundador, muy cercano a la parroquia de San Nicolás, donde fue bautizado. Allí empezaría a gestarse su vocación de docente, pues tenía un buen modelo a seguir, y los juegos entre las columnas genovesas del patio de su casa y el entorno de la cercana iglesia, parece que marcaron su posterior interés por la tipología doméstica sevillana y la arquitectura barroca religiosa, hasta el punto de dedicarle al templo su tesis de licenciatura (28-10-66) y una monografía (2008). Y también allí empezó su relación con la Semana Santa hispalense, pues quedó vinculado a la hermandad de la Candelaria, de la que llegó a ser vicepresidente de su Junta Rectora durante cinco años, por designación del entonces arzobispo fray Carlos Amigo Vallejo.

En ese colegio cursaría sus estudios hasta cuarto curso de bachillerato, para continuar, en la rama de Ciencias del bachillerato superior, en los centros "Miguel de Mañara” y "Alfonso X el Sabio", aunque sus preferencias iban por otro 
camino, cambiando a la de letras en el Pre-universitario, lo que le llevó, finalmente, a nuestra Facultad de Filosofía y Letras y a la rama de Historia General. Desde el primer curso mantuvo un estrecho contacto con Don Juan de Mata Carriazo, que también era Delegado de Excavaciones Arqueológicas del Distrito Universitario de Sevilla, que poco después, en tercer curso, le encargó inspeccionar los restos que iban surgiendo tras las notificaciones de las autoridades locales e, incluso, desde quinto, lo hacía sentar en su mesa mientras impartía las clases, para que sus compañeros "se fueran haciendo a la idea de verme como profesor".

Sin embargo, esa faceta de posible arqueólogo se trastocó al terminar sus estudios, al ofrecerle otro insigne maestro, Don José Hernández Díaz, la plaza de Profesor Ayudante de Clases Prácticas de Historia del Arte (1965), dando así un giro a su incipiente trayectoria profesional, pues Hernández Díaz era el único catedrático de esa materia, ya que Don Antonio Sancho Corbacho era adjunto y Don Antonio de la Banda ayudante.

$\mathrm{Su}$ tesis de licenciatura sobre la iglesia de San Nicolás de Bari fue galardonada con el premio Archivo Hispalense de la Diputación de Sevilla (1967) y la doctoral, dirigida por el mismo catedrático, con la colaboración de Sancho Corbacho, que llevó por título Torcuato Benjumeda y la Arquitectura Neoclásica en Cádiz, obtuvo el premio José de las Cuevas de la Diputación de Cádiz en 1973.

$\mathrm{Su}$ especialización en la historia de la arquitectura le llevó, a instancias del profesor Bonet Correa, a ser invitado por el profesor Don Rafael Manzano a colaborar con él en la Escuela Técnica Superior de Arquitectura, donde fue profesor adjunto interino y profesor encargado de cátedra, con las disciplinas de Historia del Arte e Historia de la Arquitectura y del Urbanismo (1969-1975), y fue allí donde conoció a la que es su esposa. Por esos años su labor docente se amplió enormemente, con clases en la Facultad de Filosofía y Letra, en el Colegio Universitario de Cádiz, que dependía de la Universidad de Sevilla, en la E.T.S. de Arquitectura y en el Colegio "San Antonio María Claret".

Simultáneamente intervino en el inventario artístico de la provincia de Huelva, para la Dirección General de Bellas Artes del Ministerio de Educación y Ciencia (1968-70), que coordinaba el profesor Bonet Correa, lo que le llevó a ser designado, años después, Director del Catálogo Monumental de la provincia de Huelva, por su Diputación provincial (1977), aunque sólo se publicaron monografías sobre los primeros pueblos que se inician por la A. Esas circunstancias determinaron en buena medida que su línea de investigación sobre la historia de la arquitectura se haya centrado en Andalucía occidental, gravitando en torno a las provincias de Sevilla, Cádiz y Huelva.

Su labor docente universitaria quedó fijada definitivamente cuando ganó la plaza de Profesor Adjunto en 1975, en la primera convocatoria nacional de oposiciones para Cuerpos del Estado, y la revalidó el año 2001, cuando obtuvo la cátedra universitaria. Finalmente, fue recompensado en su larga labor docente, tras la jubilación, con la plaza de Profesor Emérito Contratado (cursos 2012-2015). Se 
ha movido, por tanto, primero en la licenciatura de Historia del Arte y cursos de Doctorado, y ahora, en el Grado y Master, que también ha ampliado a la Universidad de Cádiz con cursos de Doctorado y Máster, y al Aula de la Experiencia de la Universidad de Sevilla, donde imparte Seminarios desde 2013, y en la que seguirá en el futuro demostrando su enorme dedicación a la enseñanza, dado que la legislación vigente le impide seguir desarrollándola, como sería lógico, en su propia facultad. Por ello acumula todos los méritos y distinciones que son posibles: quince trienios, seis tramos de dedicación docente y seis sexenios de investigación.

Ese magisterio le ha llevado a dirigir numerosas tesinas, TFG, TFM y las tesis doctorales de María Fernanda Morón de Castro (1992); Fernando Cruz Isidoro (1993), Amparo Graciani García (1993), Javier Rodríguez Barberán (1994), José Antonio Solís Burgos (2000), Andrés Luque Teruel (2003), y José Ángel Campillo de los Santos (2011), todas con la calificación de Sobresaliente cum laude.

Su labor de investigación le llevó a fundar en 1988 el equipo CIHAA Centro de Investigación de la Historia de la Arquitectura Andaluza HUM-171, integrado en el Departamento de Historia del Arte, del que ha sido responsable hasta 2013, que ha sido el lugar de encuentro de varios compañeros y discípulos.

Ha participado en Proyectos de I+D+I, como el de la Universidad de Málaga. Tradición e innovación. La recepción de los modelos italianos en la periferia mediterránea y su difusión. Andalucía durante la Edad Moderna (2010-2013), y encara uno nuevo, el de La Colección de Mapas, Planos y Dibujos del Archivo Ducal de Medinaceli.

Y ha obtenido diversas Becas de investigación, como la de la Fundación "Juan March" (1976); de Investigación de la provincia de Cádiz. Diputación provincial (1977); de Investigación del Monte de Piedad de Sevilla (1980); y las de Investigación de la Consejería de Cultura de la Junta de Andalucía (1991 y 1992). Y como no podía ser menos, diversos Premios, como los de Archivo Hispalense (Diputación provincial de Sevilla, 1967); José de las Cuevas (Diputación provincial de Cádiz, 1973); Accesit del premio Archivo Hispalense (1977); o el Premio Ciudad de Sevilla (Ayuntamiento de Sevilla, 1978).

Y también cuenta con una importante labor de gestión universitaria, ya que ha desempeñado, entre otras funciones, la de Secretario del Departamento de Historia del Arte desde 1985 a 1994; ha sido miembro del comité de la revista $L a$ boratorio de Arte desde sus inicios hasta 2013; dirigido Cursos de Extensión Universitaria y similares desde 1981, como los de Verano de la Universidad de Cádiz (2005-2012) o los de Otoño de la Hispalense (2007-2013); y ha sido evaluador externo de la Agencia Nacional de Evaluación y Prospectiva (ANEP) (1998-2012), del Panel de Expertos Academia de la ANECA ( 2007-2012), Experto en la Evaluación de Proyectos del Plan Gallego del I+D+i (INCITE) de la Xunta de Galicia (2007-2012) y en la Evaluación de la Axencia Galega de Innovació de la Xunta de Galicia. Área ANEP (2012). 
Sin olvidar su faceta de Comisario o Director artístico de exposiciones, como La Bahía de Cádiz en tiempos de Carlos III (Cádiz, 1988); El litoral andaluz en tiempos de Carlos III (Málaga, 1988); Magna Hispalensis. El universo de la Iglesia de Sevilla (Sevilla, 1992); El Emporio de Sevilla. IV Centenario de la construcción de la Real Audiencia (Sevilla, 1995); Universitas Hispalensis (Sevilla, 1995); Sevilla, puerto y puerta de América (Sevilla, 1996); Pedro Roldán (1624-1699). III Centenario de su muerte (Sevilla, 1999); La Inmaculada en el Arte Andaluz (Córdoba, 1999); Universidad de Sevilla. V Centenario (1505-2005) (Sevilla, 20042005); La ciudad oculta. El universo de las clausuras de Sevilla (Sevilla, 2009).

El conjunto de sus publicaciones, que sigue abierto, pues mantiene el mismo impulso, se ha visto reflejado en un extensísimo catálogo, que formalizará la addenda final de esta laudatio. Se basa en un continuado trabajo de búsqueda documental en los diferentes archivos del antiguo Reino de Sevilla (arzobispal, catedralicio, municipal, histórico provincial, parroquiales...) y de estricto análisis de la propia obra de arte y del contexto cultural y socio-económico, lo que le ha permitido estudiar biografías de arquitectos, edificios monumentales, diseños decorativos, el oficio constructivo y las tipologías, que quedan perfectamente encajados en su época. A lo que se añade el interés, complementario a su línea principal, por el resto de las artes.

$\mathrm{Su}$ investigación sobre edificios emblemáticos de la ciudad, arquitectos y la propia profesión constructiva, abarca un amplio espectro cronológico y estilístico, pues va desde el arte almohade a la época neoclásica. De la etapa almohade caben destacar los libros: La Giralda. Rosa de los Vientos (1989); VIII Centenario de la Giralda. 1198-1998 (1998) y La Torre del Oro (1983); mientras que de la gótica, resulta pionero y ejemplar, La Catedral de Sevilla. Estudio arquitectónico (1980), que ha motivado a diversos investigadores para continuar su estela sobre el edifico, o el capítulo "El edificio gótico" en La Catedral de Sevilla (1990).

Pero es la etapa barroca la que más prolífica ha resultado y ha servido de ejemplo y modelo para el autor de estas líneas, con obras tan emblemáticas como La capilla del Sagrario de la catedral de Sevilla (1977); "La ciudad barroca", dentro de La arquitectura de nuestra ciudad (1981); "La arquitectura en la Baja Andalucía”, en El arte del Barroco. Historia del Arte en Andalucía (1989); La iglesia de San Nicolás de Bari de Sevilla. Una iglesia del siglo XIII en un templo barroco (2008); o las diversas biografías y catálogos profesionales dedicados a varios arquitectos, como Torcuato Benjumeda y la arquitectura neoclásica en Cádiz. Cádiz (1974); Pedro de Silva (1979); "Leonardo de Figueroa" en Artistas andaluces y artífices del arte andaluz (2011); o El aparejador en la Historia de la Arquitectura (1981).

Fuente básica resultan sus Documentos para el estudio de la arquitectura onubense (1977), o Iglesias de la Sierra de Cádiz (1983). Y en cuanto a las tipologías, destaca su trabajo sobre faros y torres almenaras, con libros como El litoral andaluz en tiempos de Carlos III (1988), La Bahía de Cádiz en tiempos de Carlos III 
(1988) y Los faros de la costa atlántica andaluza (1989). Aunque, sin dudas, la doméstica se lleva la palma, con numerosos artículos y libros como El palacio de San Telmo (1991); El palacio Caja San Fernando, antigua Real Audiencia de Sevilla (1993); El palacio arzobispal de Sevilla (1997); El palacio de las Dueñas y las casas-palacio sevillanas del siglo XVI (2003); La casa de Jerónimo Pinelo, sede de las Reales Academias Sevillanas de Buenas Letras y de Bellas Artes (2006), o la sintética Casas de Sevilla. Desde la Edad Media hasta el siglo XVIII (2012). Sin olvidar su faceta de comisario de exposiciones, destacando catálogos como La ciudad oculta. El universo de las clausuras de Sevilla (2009).

\section{PUBLICACIONES}

\section{a) Libros y monografías}

Torcuato Benjumeda y la arquitectura neoclásica en Cádiz. Cádiz, Diputación provincial, 1974.

La capilla del Sagrario de la catedral de Sevilla. Sevilla, Diputación, 1977.

Documentos para el estudio de la arquitectura onubense. Huelva, Instituto de Estudios Onubenses "Padre Marchena”. Huelva, Diputación provincial, 1977.

La catedral de Sevilla. Madrid, Fundación “Juan March”,1979 (Serie universitaria, $\mathrm{n}^{\circ}$ 94).

Pedro de Silva. Sevilla, Diputación provincial, 1979.

La catedral de Sevilla. Estudio arquitectónico. Sevilla, Ayuntamiento/ Diputación provincial, 1980.

El aparejador en la Historia de la Arquitectura. Sevilla, Colegio Oficial de Aparejadores y Arquitectos Técnicos, 1981.

"La catedral de Sevilla". Cat. /exp. Sevilla, Monte de Piedad y Caja de Ahorros de Sevilla, 1981.

Planos y dibujos del Archivo catedral. Sevilla, Diputación provincial/ Monte de Piedad, 1982.

La Torre del Oro. Sevilla, Diputación provincial, 1983, (Arte Hispalense, 35).

Iglesias de la Sierra de Cádiz. Cádiz, Caja de Ahorros de Cádiz, 1983.

El litoral andaluz en tiempos de Carlos III. Málaga, Consejería de Obras Públicas y Transportes. Junta de Andalucía/Diputación provincial de Málaga, 1988.

La Bahía de Cádiz en tiempos de Carlos III. Cádiz, Consejería de Obras Públicas y Transportes. Junta de Andalucía/Ayuntamiento de Cádiz., 1988.

Los faros de la costa atlántica andaluza. Sevilla, Consejería de Obras Públicas y Transportes de la Junta de Andalucía, 1989.

La platería en la catedral de Sevilla. Sevilla, Universidad Internacional "Menéndez Pelayo", 1989.

Torres de almenara del Reino de Granada en tiempos de Carlos III. Sevilla, Consejería de Obras Públicas y Transportes. Junta de Andalucía, 1989. 
El palacio de San Telmo. Sevilla, Ediciones Gever, 1991.

Arquitectura barroca en Jerez. Jerez de la Frontera, Consejo Superior de Investigaciones Científicas/Centro de Estudios Históricos Jerezanos, 1993.

La iglesia de San Miguel de Jerez de la Frontera. Sevilla, Caja San Fernando, 1993. (Fascículo).

El palacio Caja San Fernando, antigua Real Audiencia de Sevilla. Sevilla, Caja San Fernando, 1993, (fascículo).

El palacio arzobispal de Sevilla. Sevilla, Caja San Fernando, 1993 (fascículo). Fernando III, rey de Sevilla. Caja San Fernando. Sevilla, 1994.

La catedral de Sevilla. Sevilla, Caja San Fernando, 1994 (fascículo).

El emporio de Sevilla. IV Centenario de la construcción de la Real Audiencia. Sevilla, Caja San Fernando, 1995.

Iglesias de Santa María y San Pedro. Arcos de la Frontera. Sevilla, Caja San Fernando, 1995, (fascículo).

Sevilla, puerto y puerta de América. Sevilla, AGESA/ Pabellón de la Navegación, 1996.

Sevilla Mariana. Sevilla, Ayuntamiento-Caja San Fernando, 1996.

El monasterio de San Isidoro del Campo. Sevilla, Caja San Fernando, 1996, (fascículo).

El palacio arzobispal de Sevilla. Córdoba, CajaSur, 1997.

Sevilla en fiestas. Sevilla, Caja San Fernando, 1997.

La Inmaculada en el arte andaluz. Córdoba, CajaSur, 1999.

Pedro Roldán (1624-1699). III Centenario de su muerte. Sevilla, Caja San Fernando, 1999.

La Giralda. Rosa de los vientos. $2^{\circ}$ edic. Sevilla, Diputación provincial, 1999, (Arte Hispalense, 50).

El palacio de las Dueñas y las casas-palacio sevillanas del siglo XVI. Sevilla, Fundación Aparejadores, 2003.

Sevilla monumental. Palacio de San Telmo. Sevilla, El Correo de Andalucía. Grupo Prisa, 44 pp. (Colección Libros y DVD, 7).

La casa de Jerónimo Pinelo, sede de las Reales Academias Sevillanas de Buenas Letras y de Bellas Artes. Sevilla, Fundación Aparejadores/ Fundación Cruz Campo, 2006.

La iglesia de San Nicolás de Bari de Sevilla. Una iglesia del siglo XIII en un templo barroco. Sevilla, Cajasol/Diputación de Sevilla, 2008.

Casas de Sevilla. Desde la Edad Media hasta el siglo XVIII. Sevilla, Maratania, 2012.

La iglesia de Santa María la Blanca y su entorno. Sevilla, Secretariado de Publicaciones de la Universidad, 2015. 


\section{b) Capítulos de libros}

“Biografía de Pedro Ángel Albisu”. Homenaje al prof. Carriazo. Tomo II. Universidad de Sevilla, 1972, pp. 181-196.

"Santuarios de la diócesis de Sevilla". Diccionario Eclesiástico de la Iglesia Española. Tomo III. Madrid, Consejo Superior de Investigaciones científicas. Instituto Enrique Flórez, 1975, pp. 2331-2332.

"Goya en el 150 aniversario de su muerte: Los Desastres de la Guerra". Catálogo de la Exposición. Museo de Bellas Artes, Sevilla, 1978.

"Arquitectura neoclásica en Andalucía". Gran Enciclopedia de Andalucía n ${ }^{\circ}$ 102. Sevilla, 1979, pp. 2534-2537.

"Planos urbanísticos del Corral de los Olmos y su entorno". Homenaje al Dr. Muro Orejón. Sevilla: Universidad, 1979, pp. 245-257.

"La ciudad barroca". La arquitectura de nuestra ciudad. Sevilla, Colegio Oficial de Aparejadores y Arquitectos Técnicos, 1981, pp. 59-80.

(con JIMÉNEZ, A.) El Giraldillo. Sevilla, Monte de Piedad, 1981. 85 pp.

(con SUÁREZ GARMENDIA, J.M.): La Torre del Oro y el río de Sevilla. Sevilla, Ayuntamiento /Fundación El Monte, 1981. 55 pp.

"La reforma barroca de la iglesia de Santa Ana". Homenaje al prof. Hernández Díaz. Tomo I. Sevilla, Universidad, 1982, pp. 381-391.

"Iglesias de la serranía gaditana”. Enciclopedia gráfica gaditana. Vol. I. n 10. Cádiz, Caja de Ahorros de Cádiz, 1984, pp. 143-161.

"El patrimonio monumental". Universidad de Sevilla. Patrimonio monumental y artístico, Sevilla, Universidad, 1986. pp. 22-59.

"Arquitectura barroca en la provincia de Huelva". El Barroco en Andalucía. Tomo III. Córdoba, Universidad, 1986, pp. 85-93.

"Prólogo" a la reedición de la Guía para visitar el Alcázar de Sevilla, de Fernán Caballero. Sevilla, Ayuntamiento, 1987.

Sevilla, imágenes de hace cien años. Equipo 28. Barcelona, 1988.

"Prólogo". El arquitecto andaluz Diego Antonio Díaz, de María del Prado Lázaro. Sevilla, Monte de Piedad. 1988, pp.4-5.

"La arquitectura en la Baja Andalucía". El arte del Barroco. Historia del Arte en Andalucía. Tomo VI. Sevilla, Ediciones Gever, 1989, pp. 270-403.

"Catedral de Sevilla". Andalucía americana. Edificios vinculados con el Descubrimiento y la Carrera de Indias. Sevilla, V Centenario del Descubrimiento de América. Junta de Andalucía, 1989, pp. 183-190.

(con otros) El agua en Sevilla. Sevilla, Ayuntamiento, 1990, 225 pp.

"Prólogo" Cat./exp. Los Cementerios en la Sevilla del siglo XIX. Sevilla, Obra Cultural El Monte, 1990, pp. 11-12.

"Edificios religiosos". Almonaster la Real. Catálogo Monumental de España. Provincia de Huelva. Huelva, Junta de Andalucía. Delegación provincial de Cultura, 1991, pp. 100-145. 
"Comisaría de la Exposición, Dirección del Catálogo, Introducción y fichas". Cat./exp. Magna Hispalensis. Madrid, Comisaría de la ciudad de Sevilla, 1992, 559 pp.

"Edificios religiosos". Alájar. Catálogo Monumental de España. Provincia de Huelva. Tomo I. Huelva, Junta de Andalucía. Delegación provincial de Cultura, 1992, pp. 45-93.

"Edificios religiosos". El Almendro. Catálogo Monumental de España. Provincia de Huelva. I.2. Huelva, Junta de Andalucía, Delegación provincial, 1992, pp. $42-79$.

"Prólogo", Arquitectura isabelina en Cádiz, de Juan Ramón Cirici Narváez. Cádiz, Ayuntamiento, 1982, pp. 9-11.

"Patrimonio monumental de las Universidades de Sevilla y Huelva". El patrimonio monumental y artístico de las universidades andaluzas. Sevilla, Junta de Andalucía 1992, pp. 25-28; 50-63; 167-169.

“Edificios emblemáticos”. Sevilla Universal. Expo’92. Sevilla, Algaida, 1992, pp. 163-181.

(con VALDIVIESO, E.) Catálogo de la Exposición Francisco Pacheco, 350 aniversario de su muerte. Sevilla, Caja San Fernando, 1994, 95 p.

(con otros) "Comisariado, Introducción y fichas". Catálogo de la Exposición Universitas Hispalensis. Sevilla, Universidad/Patronato Real Alcázar, 1995. 271 p.

"Una arquitectura para el culto". Sevilla penitente. Tomo I. Sevilla, Ediciones Gever, 1995, pp. 207-271.

"Arquitectura religiosa en Triana". Triana bajando el puente. Sevilla, Ayuntamiento, 1995 pp. 105-123 (Biblioteca de Temas Sevillanos).

"Templos para una Hermandad itinerante". Esperanza de Triana. Tomo II. Sevilla, Ediciones Guadalquivir, 1996, pp. 9-23.

"Prólogo", La iglesia de San Miguel, cinco siglos en la historia de Morón de la Frontera (XIV-XVIII), de María Fernanda Morón de Castro. Sevilla, Universidad /Fundación Fernando Villalón, 1995, p.7.

(con ARQUILLO TORRES, F.) Patrimonio recuperado de la Universidad de Sevilla. Sevilla, Universidad/Patronato del Real Alcázar, 1997, 141 pp.

"Prólogo" Arquitectura sevillana del siglo XVII. Maestros mayores de la Catedral y del Concejo hispalense, de Fernando Cruz Isidoro. Sevilla, Universidad, 1997, p. 17.

"Prólogo", Adminículo a la comprensión de Velázquez, de Andrés Luque Teruel. Sevilla, Caja San Fernando, 1998, pp. 7-10.

"Prólogo" y "Las otras Giraldas". VIII Centenario de la Giralda (1198-1998). Córdoba, Cajasur/Universidad de Sevilla, 1998, pp. 1-10 y 171-182.

"Panorama de la pintura peruana contemporánea". Cat/exp. Estilos 98. A la sombra de Sipán. Córdoba, Embajada de Perú/ Museo de Bellas Artes de Sevilla/ Cajasur, 1998. pp. 17-27. 
“La Sevilla que vio Zurbarán”. Cat./exp. Francisco de Zurbarán (1598-1664). Granada, Consejería de Cultura/ La General 1999. pp. 14-25.

"El monasterio en la Edad Moderna y Contemporánea". Real Monasterio de San Clemente: Historia, tradición y liturgia. Córdoba, CajaSur, 1999, pp. 239-291.

"El artista Joaquín Castilla (1888-1969)". 75 Aniversario de la Hermandad del Cristo de la Buena Muerte. Sevilla, Universidad /Patronato del Real Alcázar, 1999.

"Tipologías constructivas de palacios sevillanos del siglo XVI". Actas del III Congreso Nacional de Historia de la Construcción, Vol. I. Sevilla, 2000, pp. 279-285.

"La arquitectura del mar: nuevas tipologías de faros y nuevos materiales". Arquitectura y ciudad en España de 1845 a 1898. I Jornadas de Arquitectura histórica y urbanismo. Cádiz, Universidad de Cádiz/ Universidad Nacional de Educación a distancia, 2000, pp. 157-161.

"Prólogo", La técnica de la arquitectura medieval, de Amparo Graciani (Ed.). Sevilla, Universidad, 2000, pp. 10-12.

"Prólogo", Alonso de Vandelvira, tratadista y arquitecto andaluz, de Fernando Cruz Isidoro. Sevilla, Universidad, 2001, p. 11.

"El patrimonio monumental". Patrimonio Monumental y Artístico de la Universidad de Sevilla. Sevilla, Servicio de Publicaciones de la Universidad de Sevi1la, 2001, pp. 25-63.

(con otros) "Fichas catalográficas", Universidad de Sevilla. V Centenario (1505-2005). Sevilla, Universidad/Fundación El Monte, 2004, pp. 15-29.

"Prólogo, "La Inmaculada en las artes plásticas sevillanas del Siglo de Oro". La Archicofradía de Nuestro Padre Jesús Nazareno y el CL Aniversario de la Inmaculada Concepción. Sevilla, Ediciones Guadalquivir, 2004, pp. 69-95.

"El urbanismo sevillano de 1880 a 1920". La devoción a la Salud en la collación de San Nicolás de Bari. CXXV Aniversario de la llegada del Señor de la Salud a la parroquia de San Nicolás de Bari. Sevilla, Fundación Cruz Campo, 2005. pp. 29-41.

"El programa iconográfico de la iglesia de San Nicolás". Archivos de la Iglesia de Sevilla. Córdoba, Cajasur, 2006. pp. 207-222.

(con otros) "Las universidades hispánicas en tiempos del Quijote". Madrid, Comunidad de Madrid/Universidad de Alcalá, 2006, 295 pp. (fichas catalográficas).

"Arte y uso de Arquitectura". Libros del Fondo Antiguo del Laboratorio de Arte. Exposición conmemorativa del I Centenario del Laboratorio de Arte (19072007). Sevilla, Universidad, 2007, pp. 44-47.

"De baluarte a Museo Marítimo: nuevos usos y cambios de fisonomía". Torre del Oro. Madrid, Fundación FOCUS/ABENGOA, y Ediciones El Viso, 2007, pp. 23-43.

"El Barroco en Sevilla". El Barroco en Andalucía. Jornadas Europeas de Patrimonio. Granada, Consejería de Cultura. Junta de Andalucía, 2007, pp. 311-334. 
"Entre el claustro y el compás. Contenido de la Exposición” y Comisario de la Exposición y Director del Cat. La ciudad oculta. El universo de las clausuras de Sevilla. Sevilla, Fundación Cajasol, 2009, pp. 13-24, de 276 pp.

"La arquitectura en Andalucía al final del Barroco. Entre la tradición y la Academia". Tomo I. Arte, arquitectura y urbanismo Congreso Internacional Andalucía Barroca. Actas, Antequera, Junta de Andalucía, 2009, pp. 49-66.

"San Carlos Borromeo dando la comunión a los apestados de Milán". Laboratorio de Arte. 100 años de investigación del patrimonio artístico y cultural (19072007). Sevilla, Universidad /Diputación provincial, 2007, pp. 34-35.

"El patrimonio monumental de Los Lugares Colombinos". Actas de las Jornadas de Historia sobre el Descubrimiento de América. UNIA. Sede Santa María de La Rábida, 2010, pp. 126-146.

"Mármoles de talleres genoveses en las casas-palacio de Andalucía Occidental en el siglo XVI". En Creación artística y mecenazgo en el desarrollo cultural del Mediterráneo en la Edad Moderna. Málaga, Universidad, 2011, pp. 445-478.

"Leonardo de Figueroa". Artistas andaluces y artífices del arte andaluz. Tomo XXXV. Arquitectos I. La Coruña, Publicaciones comunitarias, Hércules Ediciones, 2011. pp. 203-255.

"El coleccionismo en Sevilla en el siglo XVIII". Colecciones, expolio, museos y mercado artístico en España en los siglos XVIII y XIX. Madrid, Editorial Universitaria Ramón Areces, 2011, pp. 41-64.

"La iglesia de Santa María la Blanca de Sevilla, punto de encuentro entre Murillo y Justino de Neve". Cat./exp. Murillo y Justino de Neve. El arte de la amistad. Madrid, Sevilla, Londres, Museo Nacional del Prado/Fundación Focus-Abengoa/Dulwich Picture Gallery, 2012, pp. 60-71.

"Baltasar del Río, obispo de Scala, y su capilla en la catedral de Sevilla". Patronos y modelos arquitectónicos en las relaciones de Andalucía, Roma y el Sur de Italia. Málaga, Universidad, 2012, pp.59-89.

"El Arco de la Macarena". Esperanza Macarena. Historia, Arte y Hermandad. Sevilla, Hermandad de la Macarena, 2013, pp. 98-99

\section{c) Artículos}

"Críticas de Arte". Archivo Hispalense, 138, 1966, pp. 101-114.

"La iglesia de San Nicolás de Bari, de Sevilla". Archivo Hispalense, 147-152, 1968, pp. 161-199.

"Planos de Cádiz anteriores a 1596". Archivo Español de Arte, 174, 1971, pp. 194-198.

"Colección marqués de Aracena". Museo de Arte Contemporáneo de Sevi1la/Caja de Ahorros provincial de Sevilla, 1974. 34 pp.

"Reseña", Arquitectura medieval en la Sierra de Aracena de Alfredo J. Morales. Archivo Hispalense, 180, 1976, pp. 170-171. 
"El palacio de las Dueñas” y "La Colección Osuna, de Sevilla”. Reales Sitios. Número extraordinario dedicado a Sevilla, 1977. pp. 186-195 y 260-265.

"El examen de alarife de Torcuato Benjumeda". Boletín del Museo de Bellas Artes de Cádiz, 1, 1978.

"Reseña", Juan de Arfe y Villafañe y la custodia de Sevilla, de María Jesús Sanz Serrano, Archivo Hispalense, 187, 1978, pp. 166-168.

"Reseña", Cartografía militar y maritima de Cádiz, de José Antonio Calderón y otros. Archivo Hispalense, 187, 1978, pp. 176-177.

"Reseña", Compendio de Arquitectura paleoislámica, de K.A.C. Creswell, Archivo Hispalense, 189, 1979, pp. 221-222.

"Reseña histórica". Giralda. Colegio de Arquitectos de Madrid, 1982, pp. 19-23.

"La antigua Fábrica de Tabacos (sede central de la Universidad)". Aparejadores, 9, 1982. pp. 20-27.

"Documentos inéditos sobre Diego López Bueno: La iglesia de Algodonales (Cádiz)”. Archivo Hispalense, 195, 1982, pp. 55-63.

"El edificio gótico". La catedral de Sevilla. Sevilla, Ediciones Guadalquivir, 1984. pp. 133-172.

"Plano del Guadalquivir de Fernández Angulo (1780)". Cauce 2000. Revista de Ingenieros de Caminos, Canales y Puertos, 4. Madrid, 1984.

"Prólogo", Planos y dibujos del Archivo catedral de Sevilla (siglos XVI-XX), de Rocío Luna y Concepción Serrano. Sevilla, Diputación provincial de Sevilla, 1986, pp. 8-10.

"Arquitectura barroca y neoclásica (siglos XVII-XIX)". Diccionario Enciclopédico Ilustrado de la provincia de Cádiz. Tomo I. Jerez, 1987, pp. 71-77.

"Urbanismo". Diccionario Enciclopédico Ilustrado de la provincia de Cádiz. Tomo VI Jerez de la Frontera, Caja de Ahorros de Jerez, 1987pp. 40-42.

“Jerez en el siglo XVIII". Archivo Hispalense, 217, 1988. pp. 177-197.

"La luz del mar. Faros de la costa de Cádiz y Huelva". Guadalquivir. Revista de la Compañía Sevillana de Electricidad, 7, 1987. pp. 22-27.

"Andalucía". Enciclopedia dell' Arte Medievale. Tomo I. Roma, Instituto Della Enciclopedia italiana., 1987, pp. 578-582.

"Palacios sevillanos del siglo XVI". El Monte, 4, 1988, pp. 34-41.

"La iglesia de Santa María la Blanca". Laboratorio de Arte, 1, 1988, pp. 117-132.

"Jerez en el siglo XVIII". Archivo Hispalense. 217, 1988, pp. 177-197.

"La prioral de El Puerto de Santa María". Cádiz e Iberoamérica, 7, 1989, pp. 11-18.

"La iglesia parroquial de Almonaster la Real (Huelva)". Laboratorio de Arte, 2, 1989. pp. 34-45.

"Una colección artística del siglo XVIII: la donación de don Carlos Villa a la Hermandad sacramental de San Nicolás". Archivo Hispalense, 221, 1989, pp. 185-193. 
"El legado de los Montpensier al Ayuntamiento de Sevilla". Laboratorio de Arte, 3, 1990. pp. 209-221.

"Valdés Leal y la arquitectura sevillana". Laboratorio de Arte, 4, 1991, pp. 149-168.

"Documentación de las pinturas de Juan de Espinal en la escalera del Palacio arzobispal de Sevilla". Cuadernos de Arte de la Universidad de Granada. XXIII, 1992. pp. 385-391.

"El patrimonio monumental y artístico del palacio de San Telmo". Isidorianum. Revista de Estudios Eclesiásticos Superiores, 1992, pp. 13-29.

"Un edificio gótico fuera de época: la prioral del Puerto de Santa María". Laboratorio de Arte, 5, 1992, pp. 205-223.

"Magna Hispalensis. El universo de una iglesia". Guadalquivir. Revista de la Compañia Sevillana de Electricidad, 20, 1992. pp. 30-34.

"Reseña" El arquitecto sevillano Pedro Sánchez Falconete, de Fernando Cruz Isidoro. Atrio, 4, 1992, p. 153.

"Reseña” La iglesia de Santa Ana de Sevilla, de María Ángeles Martínez Valero. Atrio, 4, 1992, pp. 156-157.

"La Torre del Oro en el siglo XIX: documentos inéditos". Laboratorio de Arte, 6, 1993. pp. 221-244.

"El nombramiento de Ginés Martínez de Aranda como maestro mayor de las diócesis de Cádiz y Santiago de Compostela". Tiempo y espacio en el Arte. Homenaje al profesor Antonio Bonet Correa. Tomo I. Madrid, Editorial Complutense, 1994, pp. 461-468.

"La Cárcel Real de Sevilla". Laboratorio de Arte, 9, 1996. pp. 157-171.

"El palacio de las Dueñas: sus orígenes. La escritura de compra-venta de 1496". Laboratorio de Arte, 10, 1997, pp. 105-123.

"Algunas puntualizaciones sobre los hospitales de los Venerables y de la Caridad". Laboratorio de Arte, 11,1998, pp. 183-195.,

"Procesión con motivo del estreno de la iglesia del Sagrario. Documento pictórico del entorno de la catedral de Sevilla en 1662". Laboratorio de Arte, 12 , 1999, pp. 143-153.

“El manuscrito de Hernán Ruíz”. El Siglo que viene, 38, 1999, pp. 59-60. pp. 6-7.

"Velázquez, libro a libro". Mercurio: Panorama de libros. Andalucía, 10, 1999,

"La proyección de la Giralda en Europa y América". La Giralda de Nueva York (1890-1925). Sevilla, Boletín Fidas. Colegio de Arquitectos de Sevilla. ${ }^{\circ}$ extraordinario. Mayo, 2001.

"La casa de los Pinelo a la luz de nuevas aportaciones documentales". Minervae Baeticae, 30, 2002, pp. 107-139.

"Reseña", de Alonso de Vandelvira (1544-ca.1626/7), tratadista y arquitecto andaluz, de Fernando Cruz Isidoro. Archivo Español de Arte, vol. LXXV, 300, 2002. 
"Iconografía, territorio y ciudad en el Cádiz del siglo XVI". Trocadero. Revista de Historia Moderna y Contemporánea, 16., 2004. pp. 311-320.

"Leonardo de Figueroa artífice de la torre del Hospital de la Caridad". Laboratorio de Arte, 16, 2004, pp. 501-506.

"El lienzo de La Adoración de la Eucaristía de la Hermandad Sacramental de la Candelaria, de Cornelio Schut". Laboratorio de Arte, 18, 2005, pp. 229-237.

"Arquitectura del mar: el universo de los faros andaluces. Costa atlántica".

Ph. Boletín del Instituto Andaluz del Patrimonio Histórico, 53, 2005, pp. 44-55.

"Falcón Vázquez, Teodoro". Diccionario de Ateneístas. Vol. III. Ateneo de Sevilla, Sevilla, Caja de Ahorros El Monte, 2005, pp. 116-117.

"El patrimonio artístico del I marqués de Loreto (1687-1772) y de la familia del Campo". Laboratorio de Arte, 19, 2006. pp. 263-287.

"Influencia de los grabados fantásticos de Dietterlin en la arquitectura barroca sevillana". Laboratorio de Arte, 21, 2009, pp. 117-134.

"La catedral de Sevilla, santuario mariano". Miriam, 362-363, 2009, pp. 129-138

"María José del Castillo, profesora e historiadora del Arte". Laboratorio de Arte, ${ }^{\circ}$ 22. Sevilla, 2010, pp. 12-16.

"Los faros de San Sebastián de Cádiz y del Morro en La Habana, en su contexto histórico y constructivo". Trocadero, 21-22, 2010, pp. 215-232.

"Pedro Romero, arquitecto del barroco sevillano (1638-1711). Laboratorio de Arte, 23., 2011, pp. 225-251.

"El canónigo Justino de Neve y la iglesia de Santa María la Blanca de Sevi1la". Laboratorio de Arte 23, 2011, pp. 589-598.

"Reseña", El patrimonio restaurado de la Basílica de la Caridad de Sanlúcar de Barrameda, de Fernando Cruz Isidoro, Archivo Hispalense, 288-290, 2013.

"Retablos y esculturas de la iglesia de Santa María la Blanca de Sevilla". Laboratorio de Arte, 25, 2013, pp.295-314.

"La portada principal del Palacio de San Telmo de Sevilla: nuevas aportaciones e interpretaciones". Diálogos de Arte. Homenaje al profesor Domingo SánchezMesa Martín, 2014, pp. 277-291.

"Pinturas murales y en lienzo de la iglesia de Santa María la Blanca de Sevi1la". Alma Ars. Estudios de Arte e Historia en homenaje al Dr. Salvador Andrés Ordax, 2013, pp. 265-272.

\section{d) Actas en congresos}

"Las restauraciones de la Giralda". I Congreso de Conservación de Bienes Culturales. Sevilla, Comité Nacional del ICOM, 1976.

"Nuevas aportaciones documentales sobre la catedral de Sevilla". I Congreso del Comité Español de Historia del Arte (CEHA). Trujillo, 1977 (CD). 
"Pedro de Silva, arquitecto diocesano de Sevilla". Actas del I Congreso de Historia de Andalucía. Andalucía Moderna (siglo XVIII). Tomo I. Córdoba, Monte de Piedad y Caja de Ahorros de Córdoba, 1978, pp. 159-172.

"Antecedentes sevillanos de iglesias fortificadas mexicanas". Actas de las II Jornadas de Andalucía y América. Tomo II. Sevilla, 1984. pp. 399-409.

"Documentos sobre jaspes utilizados en El Escorial y en el Palacio Real de Madrid, procedentes de la cuenca minera de Riotinto y su entorno". I Congreso Nacional de Minería de Riotinto. Junta de Andalucía y otros, 1988, pp. 281-297.

"La decoración de los palacios sevillanos del siglo XVI". Cuadernos de Arte e Iconografía. Actas del I Coloquio de Iconografía. Tomo II, 3. Madrid, Fundación Universitaria Española. Seminario de Arte "Marqués de Lozoya", 1989, pp. 282-288.

"Jesucristo como modelo en el programa iconográfico del Palacio de San Telmo de Sevilla". Cuadernos de Arte e Iconografía. Actas de los II Coloquios de Iconografía. Tomo IV, 7. Madrid, Fundación Universitaria Española. Seminario e Arte "Marqués de Lozoya", 1991, pp. 256-262.

"El antiguo convento de la Merced de Huelva". Actas de las XI Jornadas de Andalucía y América. Tomo II. Huelva, Diputación provincial de Huelva, 1993, pp. 221-237.

"Faros y torres de almenara en el litoral andaluz". Arquitectura e iconografía artística militar en España y América (siglos XV-XVIII). III Jornadas Nacionales de Historia Militar. Sevilla, Ministerio de Defensa. Cátedra "General Castaños", 1999, pp. 339-355.

"La casa de los Pinelo de Sevilla". Actas del XIV Congreso Nacional de Historia del Arte. Tomo I. Málaga, 2003, pp. 139-153.

"Un palacio para la Fábrica de Tabacos. Proyecto de van der Borcht de habilitar el Palacio de las Dueñas para la Administración de la Real Fábrica". Milicia y Sociedad Ilustrada en España y América (1750-1800). Actas de las XI Jornadas Nacionales de Historia Militar. Tomo II. Sevilla, Ministerio de Defensa. Cátedra “General Castaños”, 2003, pp. 439-451.

"Nuevas aportaciones documentales sobre la catedral de Sevilla". Actas del I Congreso Nacional de Historia del Arte. Trujillo, Comité Español de Historia del Arte (CEHA), 2005, CD.

"Una colección inédita de 150 planos en la catedral de Sevilla". Actas del III Congreso Nacional de Historia del Arte. Comité Español de Historia del Arte (CEHA), 2005, CD.

"El arzobispo don Jaime de Palafox y Cardona (1642-1701) y sus empresas arquitectónicas en Sevilla", Actas del Seminario internacional "Fiestas y mecenazgo en las relaciones culturales del Mediterráneo en la Edad Moderna”. Málaga, Ministerio de Economía y Competividad/Universidad de Málaga, 2012, pp. 390410. 